\title{
Assessing the Participation of Indigenous Santals People in Chapainawabganj District of Bangladesh in Income Generating Activities
}

\author{
Mithun Kumar Ghosh ${ }^{1 *}$, Afroza Awal Shoily², Md. Shafiqul Islam², Umma Musarrat \\ Misu $^{2}$ and Mst. Afroza Khatun ${ }^{2}$ \\ ${ }^{I}$ Department of Agricultural Extension and Rural Development, EXIM Bank Agricultural University, \\ Bangladesh; ${ }^{2}$ Faculty of Agriculture, EXIM Bank Agricultural University, Bangladesh \\ *Corresponding author and Email: mithunbsmrau88@yahoo.com
}

Received: 29 July 2019

Accepted: 25 December 2018

\begin{abstract}
The study was conducted to determine the participation of indigenous people in different income generating activities (IGAs) and identify their problems. The study focused especially the Santal (an indigenous community of Bangladesh) peoples living in Chapainawabganj district. A pre-structured questionnaire was used to collect data through face to face interview from randomly selected sample size of 120 respondents. The Santals did not have recognizable access to education and income generating activities (IGAs). The main findings indicate that, most of the respondents were in between $29-50$ years of age. About $60 \%$ of the respondents were illiterate with $80 \%$ belonged to medium sized family which consist of 4 to 6 members. Agriculture is the main occupation among of the respondents. Among them, only $3.33 \%$ people are involved with Government services. Most of the people are found without own land although they continue their livelihood mostly by crop production, livestock rearing, fish culture and day laboring. They take lease of cultivable land from others. The respondents had an average annual family income of about 71429BDT whereas about $80 \%$ of the respondents were under low income category. Lack of money was found the most important problem in the study area according to Focus Group Discussion (FGD). IGAs improved the overall livelihood status of the Santals in the study area.
\end{abstract}

Keywords: Participation, indigenous people, Santals, Income Generating Activities (IGAs), demographic characteristics

\section{Introduction}

Bangladesh is one of the South Asian countries with gigantic population of 144 million (Hasan et al., 2017) and who is basically rural area lead agricultural country (Hasan et al., 2015a). Bangladesh is a country of cultural and ethnic diversity, with over 54 indigenous group of peoples. The country's indigenous population is approximately 1.5 million, which represents $1.8 \%$ of the total population of the country (Bangladesh Bureau of Statistics, 2011). Indigenous people and their distinct languages, traditions, cultures, values and customs 
contribute significantly to the rich cultural heritage, ecology, and sustainable development of the country (Roy and Chakma, 2015). Acute economic hardship is prominent in most of indigenous peoples of Bangladesh. Multidimensional economic problems ranging from poverty to unemployment are faced by them. It was estimated that most of the indigenous people in the plains were landless, and large quantity were literate, about one quarter of the then national literacy rate. Most of these people are tenant or wage laborers. The Santal, formally spelt as Sonthal, an adivasi (indigenous, tribal) people and they are living predominantly in the Northern part of Bangladesh especially in the then greater districts of Dinajpur, Rangpur, Bogra, and Rajshahi. Santals are one of the most disadvantaged, vulnerable and socioeconomically poor and are the victims of severe exploitation and injustice (Elahee, 2013).

Santals are the one of the major ethnic groups in Bangladesh. They are mainly living in districts of Rajshahi division. Santals lead a poor life. They are compelled to sell their labor at a very low price in elsewhere. In addition, they dig soil, carry loads, or engage themselves in similar works of day laborers and they are accustomed to hard work. Traditionally, they are mainly agriculturists. Although the scientific side of their knowledge about cultivation and managing their land has not been developed yet. Vast majority of the Santals in Bangladesh have lost their land properties. and forcing them to earn their livelihood depending on the mercy and availability of work in the fields of their Muslim or Hindu neighbors for their mere subsistence (Murmu, 2004).

Indigenous people mostly deprived of diversified development interventions particularly in the field of Income Generating Activities. At present the main scope of IGA's are, small business, crop cultivation, tailoring, poultry rearing, cow rearing and beef fattening, homestead gardening etc. Many research shows that; agriculture dominates the tribal economic scene a very few percent are engaged in non-agricultural pursuits
(Jayakumarand and Palaniyammal, 2016). They also claimed that, these people are unable to meet their everyday requirements as they solely depend on the agricultural economy. Meanwhile, Hossain and Hasan (2018) claimed that good nutritive and medicinal valued underutilized vegetables had the capacity to enhance food security of the poor people in Bangladesh. Government and non-government organizations recently have undertaken different development programmes (such as education, infrastructural development, rural electrification, health facilities) in most of the tribal inhabited areas of Bangladesh for the development of indigenous people (Shelly 1992). Through another study Hasan et al. (2015b) on women's involvement in income generating activities in Bangladesh and exhibited that women in the study area performed different agricultural and nonagricultural income generating activities. The activities included year round vegetable cultivation, tree planting, poultry farming, cattle and goat raising, fish farming, different small cottage industries or even rice processing. Meanwhile Sultana and Hasan (2010) concluded that greater part of the women play a crucial role crop production, livestock and poultry rearing, management of fisheries, and family management.

Moreover, the Santals have very limited access for housing, education, electricity, health and sanitation, etc. In spite of many developmental programs, the economic standards of the tribal is still very low and hence, there is a need for joint efforts and better coordination of all the stake holders who are working directly or indirectly influences the development of tribal community (Seraphinus, 2014). Hence, the current study was undertaken to satisfy the following objectives.

1. To ascertain the respondent's demographic characteristics;

2. To identify the participation of indigenous people in different Income Generating Activities (IGAs) along with the problems faced by the indigenous people in the study area while operating IGAs; 


\section{Materials and Methods}

\subsection{Research design}

The present study is based on survey method. The study is confined to the Santal tribe of Chapainawabganj District. Anthropological techniques and methods such as participant observation, group discussions, interview schedule and informal conversations were taken place for this study. A semi structured interview schedule was utilized to collect responses from the respondents of the study area. Besides, for collecting data, face to face interviews and observation were carried out as this is the most commonly used method for data collection (Ogunlade and Adebayo, 2009). Delbari, Baliadanga, Babudaying andJolaharare the unions of Chapainawabganj Sadar upazilla under Chapainawabgonj districtwere selected as the study area. All Santals of the area were the population of the study. Among them 120 respondents were selected through simple random sampling technique as sample. Random sampling technique is simple and best suited for smaller population (Moore et al., 2014). The entire process of data collection was conducted from August to October, 2018.

\subsection{Measurement technique of different variables}

The variables of this study which influenced the respondent's opinion are age, educational status, family size, occupation, cultivable land, annual income and their main problems. Age of a respondent is measured in terms of actual years on the basis of their statement. Educational status was measured by the number of years of schooling. Family size referred to the total number of members of a family including the respondent himself/herself, spouse, child and other permanent dependent who lived together as family unit. Annual income of the respondents was measured in Bangladeshi taka (BDT) on the basis of total yearly earning from different agricultural and non-agricultural sources of their family. Some income generating activities were selected purposively from many the santals were engaged with and were measured using frequency. We identified their main problems using Focus Group Discussion (FGD) among 40 respondents, they were divided into four sub groups and finally ranking of the problems were done by counting scores. Overall livelihood status of the respondents was measured through percentage.

Different analysis like frequency count, means, ranges with percentages, category were administered utilizing Statistical Package for Social Science (SPSS) software to show the contribution of demographic characteristics and income generating activities of the respondents.

\section{Results and Discussion}

\subsection{Demographic characteristics of the respondents}

Respondent's demographic characteristics are accumulated into Table 1. According to the findings of Table 1 showed that average age of the respondents was 40.75 in which middle aged people percentage (about 73\%) were more. Generally the Santals are not literate have their own language known as Santali language. High percentage of Santal children dropped out from the primary level even high dropout continues progressively till the end of the primary education level, junior secondary level and the secondary and the higher secondary level. (Sharif, 2014). The findings exhibited that the $60 \%$ of the respondents were illiterate, and only $16.6 \%$ had both primary level education, and secondary level of education respectively. The condition of tribal education has been found to be very pitiable condition due to various factors, like; the remoteness, lack of educational institutions, insufficient essential educational materials, poverty, and poor health condition and so on. Poor economic condition creates great hindrance to the successful education of the tribal people (Maharana, 2015).

According to Maharana et al. (2018), family was considered to be the basic social unit which was an association of husband, wife and their children. The family was attributed with many 
important role and function like- economic, socio-cultural, psychological, and religious and many more in the society. Data contained in Table 1 demonstrated that the majority percentage $(68.3 \%)$ of respondent of the study area had family size in between 4-6 person (medium size) although the average family size of the study area was 3.3 which was lower than the national average family size (4.89) in Bangladesh is 4.89 . Generally, Santal families are nuclear type, consisting of father, mother and their unmarried children. Joint families are also not uncommon which consist of father, mother, son, daughter-in-law and their unmarried children. Father is the head of the family and the decisions are taken by him.

Data contained in Table 1 revealed that the average cultivable land was 3.325 bigha (about 110 decimal). $16.66 \%$ of the respondents had small cultivable land, $73.33 \%$ had medium cultivable land which covers the majority and $10 \%$ had high cultivable land size.

From the table it is showed that the average annual family income of the respondents was about 71429 BDT (about 893 USD), whereas the average annual income of Bangladesh is 1751 USD according to The Daily Star, 2018. Although $80 \%$ of the respondent's annual family income was low (<83680 BDT) and $18.33 \%$ of the respondents earned up to 83680-330000 BDT annually from different IGAs. Only $1.66 \%$ respondent's income was high. The major income of the Santal comes out from agriculture like paddy farming and livestock rearing. The income also comes from crop production, day labor, and business. Their wages also vary from male to female, normally male are getting 300350 tk per day, whereas the female get 250-300 tk per day.

Table 1. Demographic characteristics of the respondents

\begin{tabular}{|c|c|c|c|c|}
\hline Categories & Ranges & Frequency & Percentage $(\%)$ & Average \\
\hline \multicolumn{5}{|l|}{ Age } \\
\hline Young & $<29$ & 20 & 16.66 & \multirow{3}{*}{40.75} \\
\hline Middle & 29 to 52 & 88 & 73.33 & \\
\hline Old & $>52$ & 12 & 10 & \\
\hline \multicolumn{5}{|l|}{ Education } \\
\hline Illiterate & 0 & 72 & 60 & \multirow{4}{*}{3.3} \\
\hline Primary & 0 to 5 & 20 & 16.66 & \\
\hline Secondary & 6 to 10 & 20 & 16.66 & \\
\hline Tertiary & $>10$ & 8 & 6.66 & \\
\hline \multicolumn{5}{|c|}{ Family Size } \\
\hline Small & 2 to 3 & 30 & 25 & \multirow{3}{*}{4.46} \\
\hline Medium & 4 to 6 & 82 & 68.3 & \\
\hline Large & $>6$ & 8 & 6.66 & \\
\hline \multicolumn{5}{|c|}{ Cultivable Land } \\
\hline Small & $<2$ & 20 & 16.66 & \multirow{3}{*}{3.325} \\
\hline Medium & 2 to 5 & 88 & 73.33 & \\
\hline High & $>5$ & 12 & 10 & \\
\hline \multicolumn{5}{|c|}{ Income Status } \\
\hline Low & $<83680$ BDT & 96 & 80 & \multirow{3}{*}{71429} \\
\hline Medium & $83680-330000$ BDT & 22 & 18.33 & \\
\hline High & $>330000 \mathrm{BDT}$ & 2 & 1.66 & \\
\hline
\end{tabular}


Table 2. Income generating activities of the respondents

\begin{tabular}{lcc}
\hline Name of the IGAs & Frequency & Percentage\% \\
\hline Crop Production & 18 & 15 \\
Crop Production/Livestock & 22 & 18.3 \\
Crop Production/Livestock/Day labor & 20 & 16.7 \\
Govt Service & 4 & 3.3 \\
Day labor & 6 & 5 \\
Crop Production/Fish culture & 2 & 1.7 \\
Crop Production/Livestock/Fish culture & 8 & 6.7 \\
Crop Production/Livestock/Business & 2 & 1.7 \\
Crop Production/ Day Labor & 30 & 25 \\
Day labor/Livestock & 6 & 5 \\
Crop Production/Service & 2 & 1.7 \\
\hline
\end{tabular}

Table 3. Overall impact of IGAs on livelihood status of indigenous people

\begin{tabular}{lccc}
\hline \multirow{2}{*}{ Statement } & \multicolumn{2}{c}{ Opinion of the respondents $(\%)$} \\
\cline { 2 - 4 } & Improved & No change & Decreased \\
\hline Household income & 62 & 30 & 8 \\
Position in the society & 48 & 35 & 17 \\
Housing condition & 56 & 40 & 4 \\
Health & 52 & 35 & 13 \\
Sanitation & 70 & 30 & 0 \\
Drinking Water facilities & 75 & 23 & 2 \\
Food consumption & 55 & 45 & 0 \\
Freedom in family expenditure & 58 & 36 & 6 \\
Overall livelihood status & 60 & 34 & 6 \\
\hline
\end{tabular}

Table 4. Problem analysis through FGD in the study area

\begin{tabular}{clcccccc}
\hline \multirow{2}{*}{$\begin{array}{c}\text { S1. } \\
\text { No. }\end{array}$} & \multicolumn{1}{c}{ Problems } & \multicolumn{3}{c}{ Sub group } & \multirow{2}{*}{ Score } & \multirow{2}{*}{ Rank } \\
\cline { 3 - 6 } & & 1 & 2 & 3 & 4 & & \\
\hline 01 & Lack of Training on agricultural activities & 10 & 7 & 6 & 5 & 28 & 4 \\
02 & Lack of education institute( high school, college) & 9 & 6 & 5 & 7 & 27 & 5 \\
& near village & 5 & 5 & 10 & 4 & 24 & 6 \\
03 & Lack of help from government & 4 & 3 & 8 & 8 & 23 & 7 \\
04 & No scholarship for Santal student & 8 & 10 & 7 & 9 & 34 & 1 \\
05 & Lack of money & 6 & 9 & 6 & 10 & 31 & 2 \\
06 & Transportation problems & 1 & 1 & 2 & 3 & 7 & 10 \\
07 & Drinking water problem & 2 & 4 & 1 & 6 & 13 & 8 \\
08 & Lack of hospital or available doctor near village & 3 & 2 & 4 & 1 & 10 & 9 \\
09 & Lack of training from different agencies & 7 & 8 & 9 & 6 & 30 & 3 \\
10 & Lack of subsidy & & & & & & \\
\hline
\end{tabular}




\subsection{Income Generating Activities (IGAs) of the respondents and their impact on livelihood status in the study area}

The main purpose of this study was to find out the activities of the Santals community which they practiced to their income generation. As we observed in the study area, most of the people were engaged in agriculture. According to data presented in Table 2 about $92 \%$ of the respondents were involved in different forms of agricultural production. They actually took lease of cultivable land and did crop production and earned money by giving day labor in others field which were their main income sources. Through their studies, Shamsuddoha (2009) also found similar types of results.

From the Table 3 it is clearly indicated that majority of the indigenous people $(60 \%)$ opined that their livelihood status has improved through IGAs.

Their household income, sanitation and water facilities also increased remarkably. Many Santals $(34 \%)$ reported that involvement with IGAs does not change their livelihood status and $10 \%$ mentioned that their livelihood status in fact decreased.

\subsection{Problems analysis through Focus Group Discussion (FGD)}

A Focus group discussion (FGD) was done among 40 respondents of the study area to find their problems. After analysis of problems through FGD the important problems of the Santal people were identified and shown in Table 4. Among the problems, the most prominent problems of indigenous people of the study area was lack of money (score 34). They faced many problems relating to their day to day life. Such as among ranked problem the second highest scored problem was transportation problem. Due to this problem indigenous people cannot move easily for education, treatment etc. to outside. The third and fourth problem was lack of subsidy/ age subsidy and lack of training on agricultural issues. For these problems they are lagging behind day by day. Lack of educational institute (high school, college) near village is the next problem which needs to be solved to make indigenous people literate as well as to make them aware about their venerable condition to get rid of it.

\section{Conclusions}

The study identified the status of Santals of Chapainwabganj in respect of various parameters. Findings of the study showed majority of the respondents were illiterate having medium size family. Most of them fall under low annual income, had no own land, they took lease from others and earning their income. Agriculture was the main source of occupation in the study area. The main IGAs observed in the study area were crop cultivation, livestock rearing, fish culture. Findings from FGD demonstrated that lack of money among the respondents was the most important problem followed by transportation problems, lack of Training about agricultural activities, lack of subsidy, lack of educational institutions respectively. Alongside, overall livelihood status of the indigenous people of the study area has been improved through IGAs. Finally the study suggested that proper initiatives from policy makers are highly demanded to improve the life standard of the indigenous people creating ample income generation opportunities.

\section{References}

Bangladesh Bureau of Statistics, 2011. Population and housing census 2011, Government of the Peoples Republic of Bangladesh, Dhaka, pp. 3.

Elahee SMA. 2013. The Socio-economic Condition of Santal Community in Rajshahi, Bangladesh: A Case Study.

Hasan SS, Deng X, Li Z, Chen D. 2017. Projections of Future Land Use in Bangladesh under the Background of Baseline, Ecological Protection and Economic Development. Sustainability, 9:505. doi:10.3390/su9040505. 
Hasan SS, Ghosh MK, Arefin MS, Sultana S. 2015a. Farmers' attitude towards using agro-chemicals in rice production: A case in Laxmipur District of Bangladesh. The Agriculturists,

(2): 105 . doi:10.3329/agric.v13i2.26599.

Hasan SS., Hossain, M., Sultana, S., Ghosh MK. 2015b. Women's Involvement in Income Generating Activities and Their Opinion About Its Contribution: A Study of Gazipur District, Bangladesh. Science Innovation, doi:10.11648/j.si.20150306.13.

Hossain A. Hasan S. 2018. Potentiality of Underutilized Vegetables for Contribution to Sustainable Development Goals (SDGs) in Bangladesh. Asian Journal of Agricultural Extension, Economics \& Sociology, 26(2):1-9. doi: 10.9734/AJAEES/2018/42843.

Jayakumar A., Palaniyammal P. 2016. SocioEconomic status of scheduled tribes in Kalrayan hills. International Journal of Research-Granthaalayah, 4(3):22-30.

Maharana R. 2015. Educational Scenario among the Santhal Tribe of Mayurbhanj District, Odisha. ZENITH International Journal of Multidisciplinary Research, 5(10):4251.

Maharana R., Pate SP. 2018. The Santhal: SocioEconomic Miserable Condition and Quality of Life (An Overview of Bantali Rakhasahi Village, Mayurbhanj District, Odisha), IJRDO-Journal of Social Science and Humanities Research, 3(1):24562971.

Moore DS., George PM., Bruce C., Michael WP. 2014. Introduction to Practice of Statistics. W.H. Freeman \& Co. Ltd. USA.
Murmu, M. 2004. "The Santals: Their Traditions and Institutions in Bangladesh,"

Ogunlade I., Adebayo SA. 2009. Socioeconomic Status of Women in Rural Poultry Production in Selected Areas of Kwara State Nigeria. International Journal of Poultry Science, 8:55-59.

Roy RD., Chakma MK. 2015. National Seminar on Indigenous Peoples in Bangladesh: Human Rights and Sustainable Development Goals.

Seraphinus KA. 2014. Socio-Economic miserable condition of the tribals in Chhattisgarh: A case study of Dhanwar, Surguja district, C.G. IOSR Journal of Humanities and Social Science (IOSRJHSS); 19(6): 26-29.

Shamsuddoha M. 2009. Development of Livestock Sector through Leading NGO in Bangladesh. The Annals of the 'S tefancel Mare' University Suceava. Fascicle of the Faculty of Economics and Public Administration, 9(1): 1-9.

Sharif S. 2014. Education and skill development of santal children and youth in Bangladesh. Bangladesh Education Journal, 07-26.

Shelly MR. 1992. The Chittagong Hill Tracts of Bangladesh. Dhaka: Centre for Development Research.

Sultana S., SS. Hasan. 2010. Impact of MicroCredit on Economic Empowerment of Rural Women. The Agriculturists, 8(2): 43-49. http//banglajol.info/index.php/AGRIC/article/vie w/7576. 